Research Article

\title{
Influence of ammonium salts and temperature on the yield, morphology and chemical structure of hydrothermally carbonized saccharides
}

\author{
Kenneth G. Latham ${ }^{1,2} \cdot$ Adam Ferguson $^{1} \cdot$ Scott W. Donne ${ }^{1}$
}

(c) The Author(s) 2018 OPEN

\begin{abstract}
In this work, the influence of $\left(\mathrm{NH}_{4}\right)_{2} \mathrm{SO}_{4}$ and $\left(\mathrm{NH}_{4}\right)_{2} \mathrm{HPO}_{4}$ as well as temperature is examined on the hydrothermal carbonization of glucose, fructose and sucrose. Increasing the temperature from 160 to $220^{\circ} \mathrm{C}$ increased the yield of hydrothermal carbon for each saccharide for the $\left(\mathrm{NH}_{4}\right)_{2} \mathrm{SO}_{4}$ solution, whereas $\left(\mathrm{NH}_{4}\right)_{2} \mathrm{HPO}_{4}$ produced a yield that was independent of temperature. The addition of $\left(\mathrm{NH}_{4}\right)_{2} \mathrm{SO}_{4}$ increased the yield obtained at $220^{\circ} \mathrm{C}$ by $4.27,7.03$ and $2.01 \mathrm{wt} \%$ for glucose, fructose and sucrose over the baseline salt free solution, respectively. $\left(\mathrm{NH}_{4}\right)_{2} \mathrm{SO}_{4}$ also increased the quantity of acid produced and the average size of the hydrothermal carbon spheres. Conversely, $\left(\mathrm{NH}_{4}\right)_{2} \mathrm{HPO}_{4}$ produced carbon structures consisting of interlocked spherical shapes and produced almost no acidic products. XPS analysis revealed that $\left(\mathrm{NH}_{4}\right)_{2} \mathrm{SO}_{4}$ incorporated nitrogen and sulfur into the hydrothermal structure, while $\left(\mathrm{NH}_{4}\right)_{2} \mathrm{HPO}_{4}$ only allowed nitrogen to be incorporated. It was assessed that $\mathrm{NH}_{4}{ }^{+}$enhances the production of hydrothermal carbon, except in the presence of $\mathrm{PO}_{4}{ }^{3-}$, which prevents the reaction from effectively forming hydrothermal carbon and organic acids.
\end{abstract}

\section{Graphical abstract}

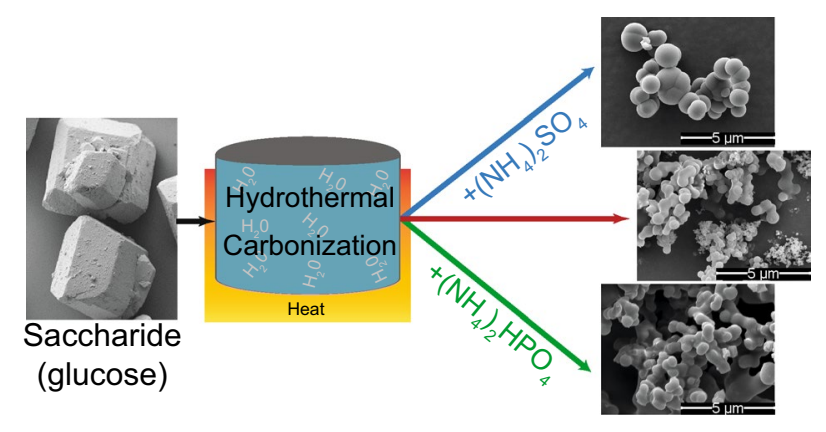

Keywords Ammonium phosphate $\cdot$ Ammonium sulfate $\cdot$ Glucose $\cdot$ Fructose $\cdot$ Sucrose $\cdot$ FTIR $\cdot$ XPS

Kenneth G. Latham, Kenneth.Latham@umu.se | 'Discipline of Chemistry, University of Newcastle, Callaghan, NSW 2308, Australia. ${ }^{2}$ Department of Chemistry, Umeå University, 90187 Umeå, Sweden. 


\section{Introduction}

Hydrothermal carbonization has gained significant interest over the last 10 years for its ability to synthesize functionalized carbon materials at low temperatures $\left(150-350^{\circ} \mathrm{C}\right)$ from a wide variety of carbon precursors [1-5]. The resultant materials include micro and mesoporous carbons [6-9], hollow carbon spheres [10], non-metal doped carbons [1, 11-14], carbon gels $[15,16]$ and cabbage or flower-like carbon materials $[5,8,17]$. This has resulted in hydrothermal carbons (HTC) being utilized in wide range of applications such as catalysts [10], adsorbents [2], $\mathrm{CO}_{2}$ capture [12], fuels [3], batteries and electrochemical capacitors $[4,6-8,13-17]$.

The wide range of carbonaceous structures from hydrothermal carbonization is due to the versatility and tunable nature of the hydrothermal reaction. This process consists of heating carbon containing precursors under water and self-generated pressures below the critical point of water $\left(374{ }^{\circ} \mathrm{C}\right)$. Through changing the reaction conditions, such as temperature, reaction time and $\mathrm{pH}$, the properties of hydrothermal carbons are easily modified. For example, raising the reaction temperature increases both the yield and hydrothermal carbon sphere size [18], while adding $\mathrm{Na}_{2} \mathrm{SO}_{4}$ has been shown to enhance the yield of HTC at the same temperature [19]. Changes to the spherical nature of HTC can also be achieved through adding various precursors [i.e., $\mathrm{Co}(\mathrm{acac})_{2}$ ] into the solution prior to carbonization [5]. Nevertheless, some additions to the hydrothermal solution are detrimental to hydrothermal carbon production. For example, previous work has shown that the addition of $\mathrm{NaOH}$ reduces the yield of HTC considerably [11], while $\mathrm{NaCl}$ seems to have limited effect on enhancing the yield of HTC [19]. Furthermore, the addition of dopants into the carbon structure (i.e., nitrogen, phosphorus and sulfur) have been shown to enhance the properties of hydrothermal carbons in electrochemical capacitors [13, 14] and oxygen reduction catalysts [20]. It is for this reason that examining the effects of various dopants and additives is important to understanding their influence on hydrothermal carbonization and the resultant carbonaceous product.

In terms of the sheer number of investigations, nitrogen is one of the most examined dopants for hydrothermal carbonization, due to its natural abundance in hydrothermal precursor materials (i.e., chitosan [12], tannin [21]) as well as having a wide variety of soluble nitrogen containing compounds (i.e., urea [22], $\left.\left(\mathrm{NH}_{4}\right)_{2} \mathrm{SO}_{4}\right)$ [11]). However, research examining dopants for nitrogen doped hydrothermal carbonization tends to of been focused on single precursor. The lack of studies examining multiple nitrogen precursors makes it difficult to effectively compare the effects of these precursors on hydrothermal carbonization, as hydrothermal carbonization conditions are not standard. Thus, in this work we examine the effects of $\left(\mathrm{NH}_{4}\right)_{2} \mathrm{SO}_{4},\left(\mathrm{NH}_{4}\right)_{2} \mathrm{HPO}_{4}$ and $\mathrm{Na}_{2} \mathrm{SO}_{4}$ on the hydrothermal carbonization of glucose, fructose and sucrose.

\section{Materials and methods}

\subsection{Hydrothermal precursor solutions}

Four non-nitrogenated saccharide solutions were prepared by dissolving solid sucrose ( $34.23 \mathrm{~g}$, Sigma Aldrich, $\geq 99.0 \%$ ), glucose (18.02 g, Sigma Aldrich, $\geq 99.0 \%$ ), fructose (18.02 g, Sigma Aldrich, $\geq 99.0 \%)$, or a combination of glucose $(9.01 \mathrm{~g})$ and fructose $(9.01 \mathrm{~g})$ in of $1 \mathrm{~L}$ of Milli-Q ultrapure water (resistivity $>18.2 \mathrm{M} \Omega \mathrm{cm}$ ) to give a final concentration of $0.1 \mathrm{M}$. The non-nitrogenated hydrothermal carbons are referred to as $F, G, S, G+F$, for fructose, glucose, sucrose and glucose + fructose with their respective hydrothermal carbonization temperatures (i.e., F200 is fructose at $200^{\circ} \mathrm{C}$ ).

Nitrogenated solutions were prepared by dissolving solid $\left(\mathrm{NH}_{4}\right)_{2} \mathrm{SO}_{4}$ (26.43 g, Sigma Aldrich, $\geq 98.0 \%$ ) or $\left(\mathrm{NH}_{4}\right)_{2} \mathrm{HPO}_{4}(26.412 \mathrm{~g}$, Sigma Aldrich, $\geq 98.0 \%)$ into each of the four saccharide solutions to produce a solution containing of $0.1 \mathrm{M}$ saccharide and of $0.2 \mathrm{M}$ ammonium salt. The nitrogenated hydrothermal carbons are denoted with AS or AP for $\left(\mathrm{NH}_{4}\right)_{2} \mathrm{SO}_{4}$ or $\left(\mathrm{NH}_{4}\right)_{2} \mathrm{HPO}_{4}$ (i.e., FAS200 is fructose with $\left(\mathrm{NH}_{4}\right)_{2} \mathrm{SO}_{4}$ at $\left.200^{\circ} \mathrm{C}\right)$.

\subsection{Hydrothermal synthesis}

$15 \mathrm{~mL}$ aliquots of the hydrothermal precursor solutions were placed in a Teflon-lined steel bomb reactor with an internal volume of $23 \mathrm{~cm}^{3}$. The bomb reactor was sealed and heated in an oven at temperatures between 160 and $220^{\circ} \mathrm{C}$ for $4 \mathrm{~h}$. After this period, the oven was opened and allowed to cool quickly to ambient temperature. Quenching the reactors quicker would of resulted in the release of the hydrothermal contents. The insoluble product (denoted as hydrothermal carbon) was collected by filtration and washed thoroughly with Milli-Q ultra pure water and acetone, to remove any salts and organic compounds that have precipitated on the carbon surface, before being dried at $110^{\circ} \mathrm{C}$ overnight. The final solid product was weighed after drying to obtain yield. Each hydrothermal carbon sample was synthesized three times and the average of their yields is reported. The liquid phase, pre- and post-hydrothermal treatment, was $\mathrm{pH}$ tested to 
determine the overall acid contribution from the hydrothermal process.

\section{3 pH measurements}

The $\mathrm{pH}$ data was obtained using a $\mathrm{pH}$ box and probe, and calibrated using $\mathrm{pH}$ standard solutions of $\mathrm{pH} 4.0$ and $\mathrm{pH}$ 7.0, at ambient temperature. The $\mathrm{pH}$ of the starting solutions and post hydrothermal solutions was measured. Solutions were stirred before measurements taken to ensure homogeneity.

\subsection{GCMS}

A $1 \mu \mathrm{L}$ sample of the liquid phase from G180, G220, F180, F220, S180 or S220 was injected into a Shimadzu GC-MS QF2010 El/NCl system fitted with a ZB-5MS column $(30 \mathrm{~m} \times 0.25 \mathrm{~mm})$ with a $5 \%$ phenylarylene stationary phase. A temperature program was set to rest at $50^{\circ} \mathrm{C}$ for $2 \mathrm{~min}$ before increasing in temperature at $25^{\circ} \mathrm{C} / \mathrm{min}$ until $200^{\circ} \mathrm{C}$ was reached, where it was held constant for $7 \mathrm{~min}$. The solvent cutoff was set to $2 \mathrm{~min}$, with the mass spectroscopy detector set to record after this time. Qualitative compound determination was performed by comparing the resulting $\mathrm{m} / \mathrm{z}$ spectra to the NIST 09 database. Quantitative analysis was performed on 5-hydroxymethylfurfural (Sigma Aldrich $\geq 99.0 \%$ ) and levulinic acid (Sigma Aldrich $\geq 98.0 \%$ ) using calibration standards ranging in concentrations from 0.1 to $250 \mathrm{mMol} \mathrm{L}^{-1}$, prepared from pure samples.

\subsection{FTIR spectroscopy}

FTIR spectra of the hydrothermal carbons were recorded on a Perkin Elmer Spectrum Two IR Spectrometer equipped with a diamond ATR crystal. The sample was placed on the diamond crystal of the detector where force was applied until a spectrum was adequately resolved. The sample was scanned 8 times between 4000 and $450 \mathrm{~cm}^{-1}$ and ATR and background corrected using Perkin Elmer Spectrum 10 software.

\subsection{X-ray photoelectron spectroscopy}

The X-ray Photoelectron Spectroscopy (XPS) measurements were performed using a Thermo ESCALAB250i $\mathrm{X}$-ray photoelectron spectrometer in an ultrahigh vacuum $\left(1 \times 10^{-9} \mathrm{~Pa}\right)$ system equipped with a hemispherical analyzer. Three hydrothermal carbon samples, S200, AS200 and AP200, were mounted on indium then degassed and transferred into the analysis chamber. An unmonochromated Mg Ka X-ray source of incident energy $1253.7 \mathrm{eV}$ was applied to generate core excitation. The spectrometer was calibrated assuming the binding energy (BE) of the $\mathrm{Au}_{7 / 2}$ line at $84.0 \mathrm{eV}$ with respect to the Fermi level. The standard deviation for the BE values was $0.1 \mathrm{eV}$. Survey scans ( $1 \mathrm{eV} /$ step) were obtained in the $0-750 \mathrm{eV}$ range and used to determine the surface composition. Detailed scans ( $0.25 \mathrm{eV} / \mathrm{step})$ were recorded for the $\mathrm{O} 1 \mathrm{~s}, \mathrm{C} 1 \mathrm{~s}$ and $\mathrm{N} 1 \mathrm{~s}$ regions. Spectra were analyzed and processed using CasaXPS 2.3.16 software with full width half maximum (FWHM) for synthetic peaks in $\mathrm{O} 1 \mathrm{~s}, \mathrm{C} 1 \mathrm{~s}$ and $\mathrm{N} 1 \mathrm{~s}$ identified using calibration standards. The background was approximated by a Shirley algorithm and the detailed spectra were fitted with Gaussian-Lorentzian functions. Peak assignments were based previous XPS work on hydrothermal carbon $[1,11]$.

\subsection{Morphological analysis}

The morphology and size were examined with a Philips XL30 scanning electron microscope (SEM) at different magnifications. Hydrothermal carbon samples were mounted on aluminum stubs with double sided carbon tape and gold coated at four different angles to ensure complete coverage of gold around the microspheres.

Sizing of the hydrothermal carbons was performed using Image J software on the $10,000 \times$ magnification images of each hydrothermal carbon. The software inserts ellipses around each hydrothermal carbon microsphere and measures the pixels across the major and minor axes, comparing these to the number of pixels in the scale bar. A total of $\sim 250$ individual microspheres were chosen at random for sizing measurements.

\section{Results and discussion}

\subsection{Yield of hydrothermal carbons and acid production}

Figure 1 displays the hydrothermal carbon yield ( $w t \%)$ at increasing temperatures obtained with (a) no nitrogen, (b) $\left(\mathrm{NH}_{4}\right)_{2} \mathrm{SO}_{4}$ and (c) $\left(\mathrm{NH}_{4}\right)_{2} \mathrm{HPO}_{4}$. For the non-nitrogenated environment (Fig. 1a) HTC yield for all saccharides other than glucose, increased with increasing temperature. The HTC yield for glucose remained below 6 wt\% until the temperature was raised $220^{\circ} \mathrm{C}$, in which the yield rose to $21 \mathrm{wt} \%$.

To understand the difference in yields and the influence of ammonia salts the overall mechanism of hydrothermal carbon formation will be discussed. The formation of hydrothermal carbon can be broken into two main stages, decomposition/fragmentation of the precursor into intermediates (e.g., hydroxymethylfurfural (HMF)) and polymerization of intermediates into solid 

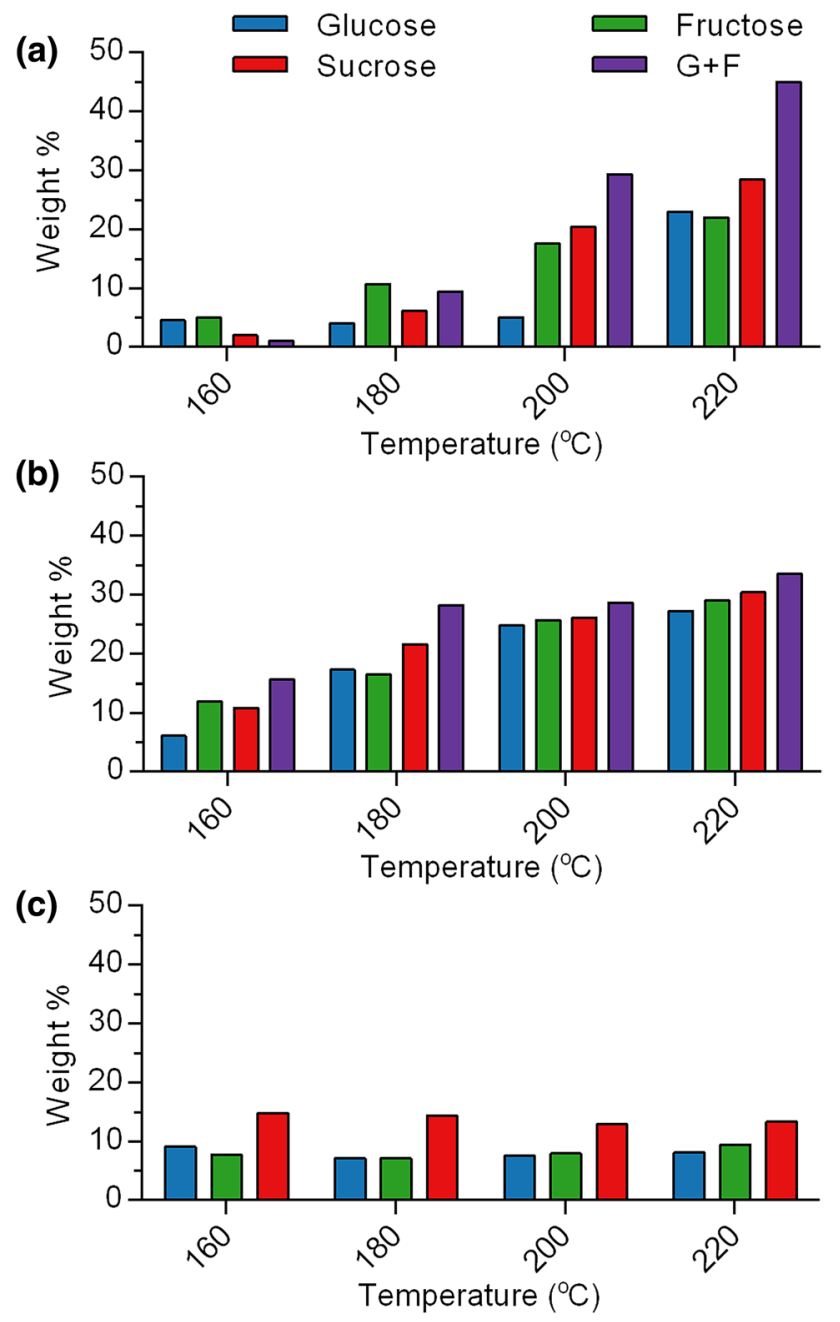

Fig. 1 Average yields in wt\% of each of the selected precursors hydrothermally carbonized in the presence of $\mathbf{a}$ no nitrogen, $\mathbf{b}$ $\left(\mathrm{NH}_{4}\right)_{2} \mathrm{SO}_{4}$, and $\mathbf{c}\left(\mathrm{NH}_{4}\right)_{2} \mathrm{HPO}_{4}$

carbon particles (Fig. 2). For mono, di and polysaccharides, the most important intermediate is the formation of hydroxymethylfurfural (HMF). HMF undergoes a series of polymerization, condensation and aromatization steps to form the furanic structural backbone of hydrothermal carbon $[1,23]$. A detailed explanation of the breakdown steps can be found in studies by [24-26] and formation steps in studies by [27-29]. As a result, any factor that impedes or enhances the formation of HMF can have a negative impact on HTC formation. However, this is not the only char formation pathway, with aldehydes, ketones and phenols also forming that can participate in polymerization/condensation reactions. In addition to these products, several organic acids are produced that are not incorporated into the char structure and are seen as by-products to char formation.

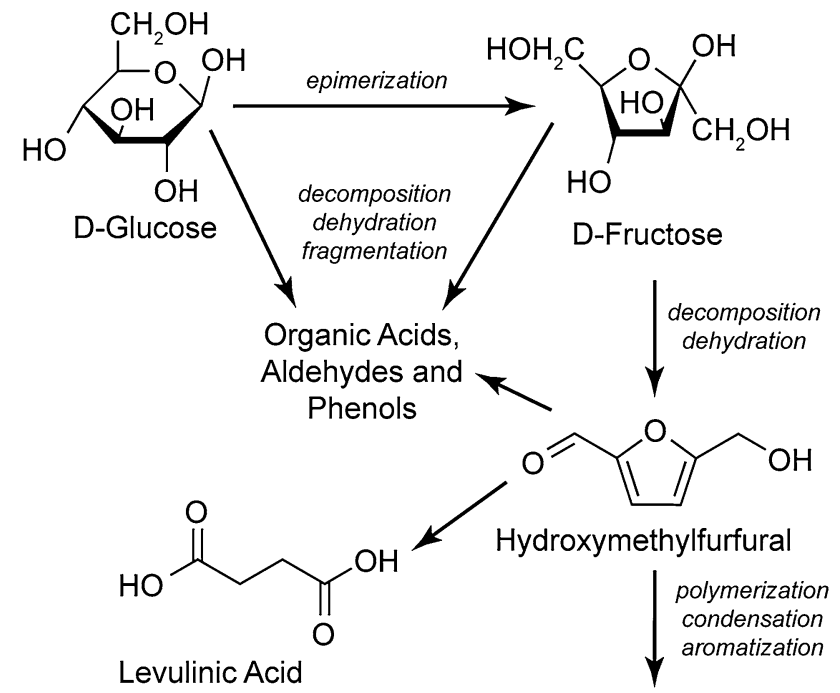

Hydrothermal Carbon

Fig. 2 Simplified reaction mechanism for hydrothermal carbon from glucose or fructose displaying the main compounds formed and reaction pathways

Although the overall mechanism is similar for each of the precursors in this study, the initial breakdown step is different, leading to slightly different reaction rates. For sucrose, the glycosidic linkage between the glucose and fructose subunits is broken first, leaving a fructofuranosyl cation and glucose molecule. The cation is highly reactive and increasing the rate of HMF formation and decomposition of sucrose [30, 31]. For glucose, epimerization into fructose is the first step before it forms HMF, while fructose forms HMF directly (Fig. 2) [32, 33]. The reduction in char formation in glucose at lower temperatures is attributed to the epimerization step, which is rate limiting below 210 , and is the reason for the decrease in yield relative to fructose at $160^{\circ} \mathrm{C}, 180^{\circ} \mathrm{C}$ and $200^{\circ} \mathrm{C}$. However, to assess whether this is occurring here, glucose was hydrothermally carbonized from 160 to 220 at $10{ }^{\circ} \mathrm{C}$ intervals. It can be seen in Fig. 3 that the yield of the glucose sample increases

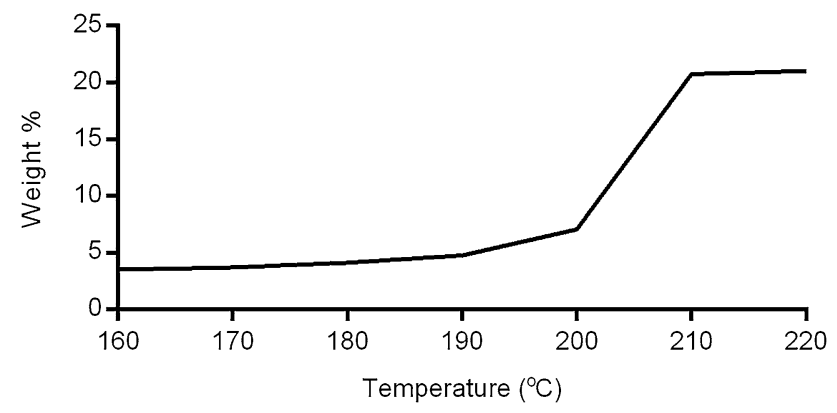

Fig. 3 Yield of glucose $\mathrm{HTC}$ at $10^{\circ} \mathrm{C}$ temperature intervals clearly showing the increase in yield at $210^{\circ} \mathrm{C}$ 
considerably at $210^{\circ} \mathrm{C}$, suggesting that the lack of HTC produced from glucose at low temperatures is attributed this additional epimerization step.

Regarding sucrose under non-nitrogenated conditions (Fig. 1a), the yield was observed to be lower than fructose at $160^{\circ} \mathrm{C}$ and $180^{\circ} \mathrm{C}$, while producing slightly higher yields to both the monosaccharides at $200^{\circ} \mathrm{C}$ and $220^{\circ} \mathrm{C}$. The lower yields are attributed to the additional energy required to cleave the glycosidic bond in sucrose [30], followed by the epimerization of glucose to fructose. The effect of this additional step for sucrose is evident in the $G+F$ series (Fig. 1a), where the yield is higher for $G+F$ in comparison to sucrose. Interestingly, the $G+F$ series also produces higher yields than all other saccharides at $200^{\circ} \mathrm{C}$ and $220^{\circ} \mathrm{C}$. This suggests that the byproducts from the decomposition of fructose, which would occur before glucose decomposition, may assist with the decomposition of glucose. This is likely to occur via the organic acids produced from fructose decomposition as the production of important intermediates, such as 5-hydroxymethylfurfural, are acid catalyzed and increases with decreasing $\mathrm{pH}$ $[26,34,35]$.

To examine the effect of organic acids produced in situ, $\mathrm{pH}$ readings were taken prior to and after hydrothermal carbonization and converted into $\mathrm{H}^{+}$produced. As the acids formed under hydrothermal carbonization are weak acids (i.e., formic acid, acetic acid, propanoic acid, levulic acid), their pKa and the final $\mathrm{pH}$ of the solution must also be considered. The pKa of the main organic acids identified in hydrothermal carbonization is displayed in Table 1.

Considering the final $\mathrm{pH}$ of each of the final hydrothermal solutions is below the pKa, the equilibrium between the protonated and deprotonated forms is shifted towards the protonated form. Thus, to decrease the $\mathrm{pH}$ of the solution below the pKa of the acids produced in hydrothermal carbonization requires an increasingly larger quantity of acid. To validate this, hydrothermal solutions for G180, F180, S180 G220, F220 and S220 were quantitatively analysied by GCMS for levulinic acid and HMF (Table 2). The rationale behind quantifying the amount of HMF and levulinic acid

Table 1 List of common organic acids with their pKa found in solution after hydrothermal carbonization

\begin{tabular}{lll}
\hline Organic acid & pKa & References \\
\hline Formic acid & 3.75 & {$[29,33,36,37]$} \\
Lactic acid & 3.86 & {$[29,36,38-40]$} \\
Acetic acid & 4.76 & {$[29,33,36,37$,} \\
& & $39,41]$ \\
Propanoic acid & 4.87 & {$[29,40]$} \\
Levulinic acid & 4.78 & {$[29,36,37,41]$} \\
Acrylic acid & 4.25 & {$[29,40]$} \\
\hline
\end{tabular}

Table 2 Concentration of hydroxymethyfurfural (HMF) and levulinic acid found in hydrothermal solutions after carbonization for various saccharides carbonized at 180 and $220^{\circ} \mathrm{C}$

\begin{tabular}{lrllll}
\hline Sample & HMF $(\mathrm{mM})$ & $\begin{array}{l}\text { Levulinic } \\
\text { acid (mM) }\end{array}$ & Initial $\mathrm{pH}$ & Final $\mathrm{pH}$ & $\begin{array}{l}{\left[\mathrm{H}^{+}\right]^{*}} \\
\text { produced } \\
\text { (mmol) }\end{array}$ \\
\hline $\mathrm{G} 180$ & 52.75 & 1.49 & 4.83 & 2.99 & 1.01 \\
$\mathrm{G} 220$ & 7.02 & 24.55 & 4.80 & 2.63 & 2.33 \\
$\mathrm{~F} 180$ & 9.54 & 33.14 & 4.01 & 2.59 & 2.47 \\
$\mathrm{~F} 220$ & 5.14 & 30.94 & 4.74 & 2.65 & 2.22 \\
$\mathrm{~S} 180$ & 48.26 & 46.79 & 4.62 & 2.40 & 3.96 \\
S220 & 5.14 & 95.23 & 4.28 & 2.23 & 5.84 \\
\hline
\end{tabular}

*Calculated from the $\left[\mathrm{H}^{+}\right]$difference between the initial $\left[\mathrm{H}^{+}\right]$from $\mathrm{pH}$ and final $\left[\mathrm{H}^{+}\right]$in solution from $\mathrm{pH}$

remaining in the solution is that HMF has been shown to produce HTC, and levulinic acid is a competing process from the decomposition of HMF [42-44]. It can be seen from Table 2, that the lower the final $\mathrm{pH}$, the higher the level of levulinic acid in solution. This relationship is exponential, confirming the previous conclusion that as $\mathrm{pH}$ decreases, the level of organic acids in the solution increases exponentially.

Comparing the $\mathrm{H}^{+}$produced for the non-nitrogenated solutions (Fig. 4), $\mathrm{H}^{+}$production increases with temperature, except for fructose, which remains almost constant after $180^{\circ} \mathrm{C}$. This would suggest that the reaction pathways towards acid production from fructose have gone to completion at $180^{\circ} \mathrm{C}$. For the $\mathrm{G}+\mathrm{F}$ sample, it can be seen that the $\mathrm{H}^{+}$produced is higher than both glucose and fructose, indicating that fructose is assisting in the decomposition of glucose. If fructose was not assisting, the level of acid production would be expected to be approximately the same as the fructose sample at $160^{\circ} \mathrm{C}$, as glucose had not begun to degraded at this point.

The addition of $\left(\mathrm{NH}_{4}\right)_{2} \mathrm{SO}_{4}$ was found to increase the yield of HTC across all saccharides, particularly at lower temperatures (Fig. 1b), for example SAS160 produced $10.84 \mathrm{wt} \%$ whereas $\mathrm{S} 160$ only produced $2.01 \mathrm{wt} \%$. In addition to increased yields, the temperature restriction highlighted earlier for glucose to form HTC only appears at $160^{\circ} \mathrm{C}$.

The increase in yield here is likely from the presence of $\mathrm{NH}_{4}{ }^{+}$and subsequently $\mathrm{NH}_{3}$. These compounds have been shown to produce cascading Maillard reactions under hydrothermal conditions, providing additional reaction paths for char formation [1, 45]. Additionally, $\mathrm{NH}_{3}$ is known to participate in ring opening reactions on glucose (Amadori rearrangement), which may remove the need for glucose to be epimerized to fructose before forming hydrothermal carbon and explain the increased yield for glucose at lower temperatures. In 
(a)

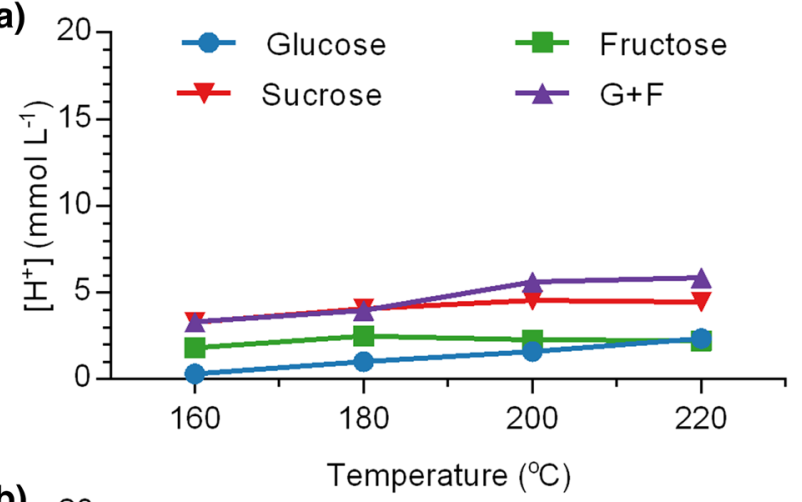

(b)

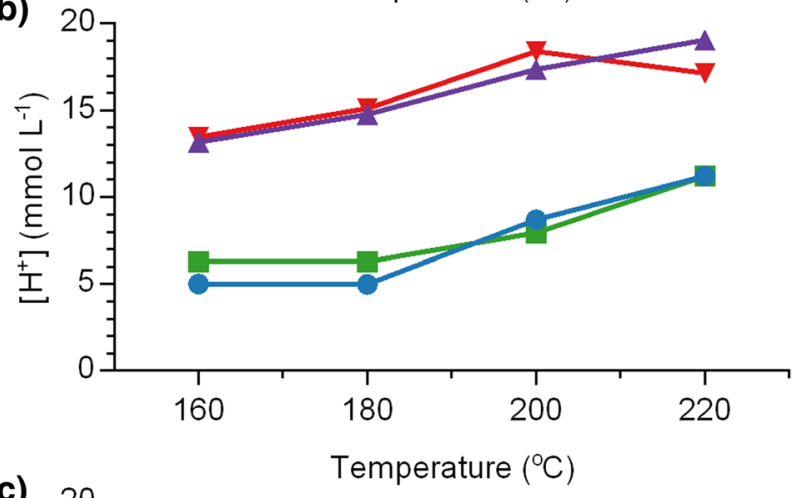

(c)

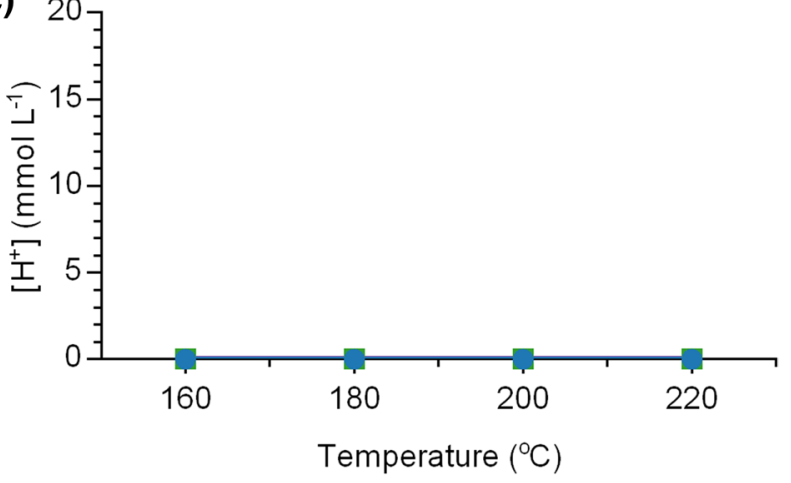

Fig. $4\left[\mathrm{H}^{+}\right]$produced in each hydrothermal carbonization calculated from the $\mathrm{pH}$ reading prior to heating and after heating for a no nitrogen, $\mathbf{b}\left(\mathrm{NH}_{4}\right)_{2} \mathrm{SO}_{4}$, and $\mathbf{c}\left(\mathrm{NH}_{4}\right)_{2} \mathrm{HPO}_{4}$

regard to organic acid formation (Fig. 4b), the presence of $\left(\mathrm{NH}_{4}\right)_{2} \mathrm{SO}_{4}$ also increased the degree of $\mathrm{H}^{+}$in solution.

Interestingly, the addition of $\mathrm{NH}_{4}{ }^{+}$from $\left(\mathrm{NH}_{4}\right)_{2} \mathrm{HPO}_{4}$ produced an entirely different effect on the yield of HTC across all saccharides. The yield at $160^{\circ} \mathrm{C}$ was greater than the other series, but was almost constant regardless of temperature. There were slight differences between saccharides, with sucrose producing higher yields than both fructose and glucose. Considering that $\mathrm{NH}_{4}{ }^{+}$has been shown to have an enhancing effect on the production of $\mathrm{HTC}$, the lack of yield in the presence of $\left(\mathrm{NH}_{4}\right)_{2} \mathrm{HPO}_{4}$ clearly indicates the impact of the $\mathrm{PO}_{4}{ }^{3-}$ anion on hydrothermal carbonization.
Further insight can be gained by examining the $\mathrm{H}^{+}$ produced for $\left(\mathrm{NH}_{4}\right)_{2} \mathrm{HPO}_{4}$ (Fig. 4c), where almost no $\mathrm{H}^{+}$ is formed in solution. The $\left(\mathrm{NH}_{4}\right)_{2} \mathrm{HPO}_{4}$ solutions were the only solutions to start with an alkaline $\mathrm{pH}$ in between 7.5 to 8.0 and had a final pH between $\mathrm{pH} 6$ to 6.4 for glucose and fructose, and $\mathrm{pH} 4.0$ to 4.5 for sucrose. As the final $\mathrm{pH}$ is above or close to pKa of the common organic acids (Table 1), these acids are likely to be in their deprotonated form and produce a larger impact on the $\mathrm{pH}$. The lack of $\mathrm{H}^{+}$production suggests that $\mathrm{PO}_{4}{ }^{3-}$ inhibits on the hydrothermal carbonization mechanism prior to the formation of organic acids or significantly hinders their production.

The effect of the anion on the yield was also found by Ming et al., when examining the effects of $\mathrm{NaSO}_{4}, \mathrm{NaCl}$ and $\mathrm{NaNO}_{3}$ on the hydrothermal carbonization of glucose [19]. The yield varied depending on the sodium salt used, however the $\mathrm{pH}$ fell considerably for all salts, indicating the production of organic acids was not impacted by these anions. This indicates that an entirely different mechanism is occurring under $\mathrm{PO}_{4}{ }^{3-}$. The reaction rate is initially faster than the neutral or $\left(\mathrm{NH}_{4}\right)_{2} \mathrm{SO}_{4}$ solutions (high yield at $160^{\circ} \mathrm{C}$ ), before being stopped when the yield of HTC reaches $10-15 \mathrm{wt} \%$. Unfortunately, yield and $\mathrm{pH}$ data are not enough to fully understand how $\mathrm{PO}_{4}{ }^{3-}$ influences $\mathrm{HTC}$ and this is best suited for a subsequent study examining multiple $\mathrm{PO}_{4}{ }^{3-}$ salts using NMR to fully understand the structural differences and hydrothermal liquid changes.

\subsection{SEM images and sizing}

The formation of HTC is a complex series of hydrophobic ripening [28], dies alder [29], aldol addition [25], dehydration $[18,29]$ and polymerization reactions $[24,46]$. These reactions, and the HTC material resulting from them have been shown to be influenced by the feedstock type [18, 47], temperature [18], residence time [18], $\mathrm{pH}$ [11] and dopants $[1,11,29]$. This allows the morphology of HTC materials to be tailored towards specific sizes and shapes and is reflected in the morphology of the different HTC series produced at $220^{\circ} \mathrm{C}$ (Fig. 5).

The hydrothermal carbonization of saccharides formed predominately spherical particles, however differences between HTC's can be noted in both the size of the spheres and their interconnectivity. The most significant difference is seen in the $\left(\mathrm{NH}_{4}\right)_{2} \mathrm{HPO}_{4}$ series, where fully formed spherical particles are not apparent. Instead, a series of interconnected spherical shapes form a bulk macro structure. To further examine the differences in morphology, the spherical size distribution was calculated from measuring 250 spheres across multiple SEM images of each sample (Fig. 5). For the non-nitrogenated HTC, a broad distribution of sizes between 1 and $10 \mu \mathrm{m}$ can be observed for each saccharide. However, the glucose, sucrose and fructose 

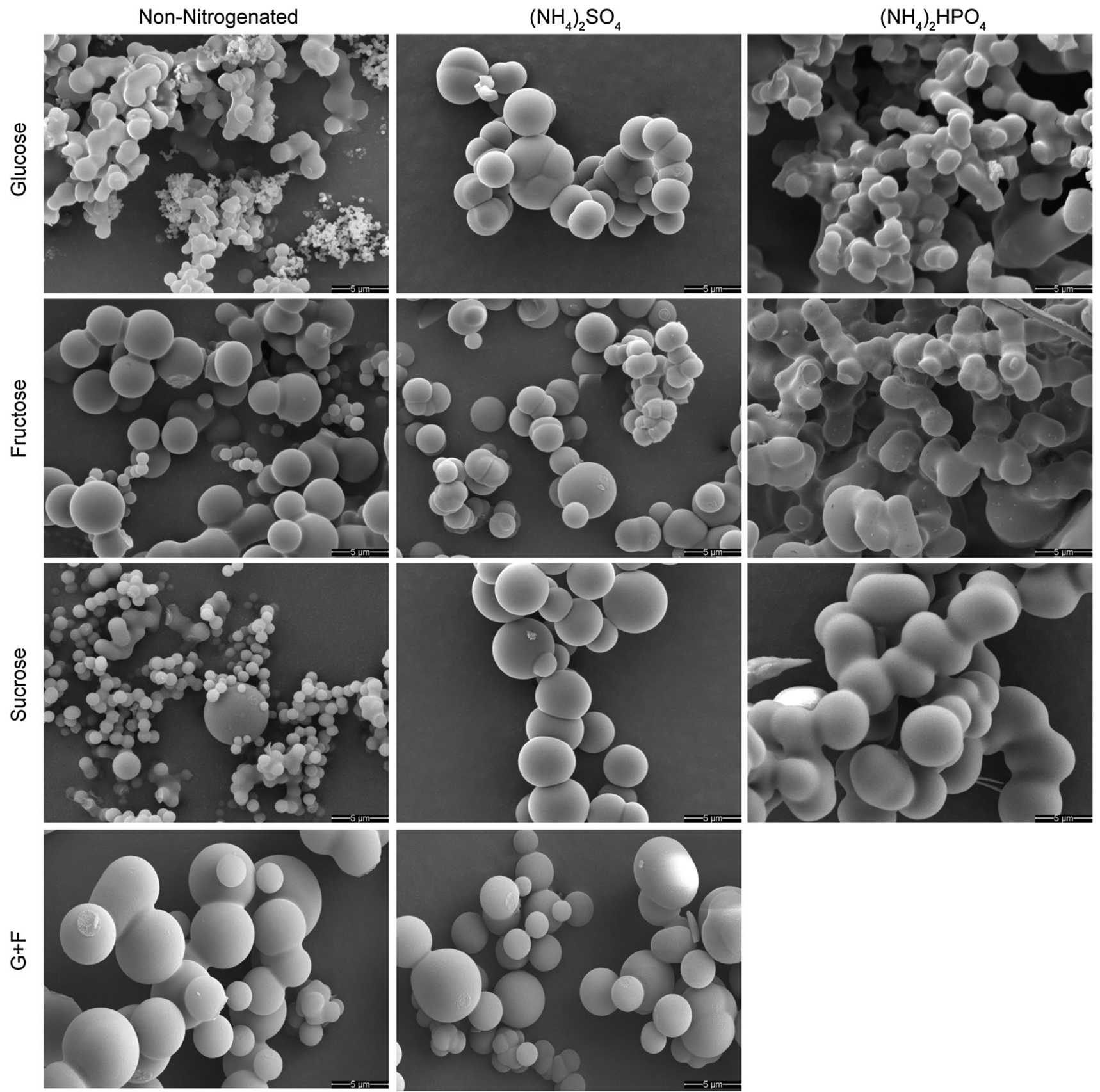

Fig. 5 SEM images of each $\mathrm{HTC}$ produced at $220^{\circ} \mathrm{C}$, the scale bar is $5 \mu \mathrm{m}$

HTC tend to have a larger distribution between 0 and $2 \mu \mathrm{m}$ with their mean between 1.6 and $2.8 \mu \mathrm{m}$ (Table 3), while the mean of G + F HTC was significantly higher.

The addition of nitrogen into the hydrothermal solution allows mallard reactions to occur $[29,45]$, which will also affect the growth of HTC materials. The effect with $\left(\mathrm{NH}_{4}\right)_{2} \mathrm{SO}_{4}$ on HTC size and growth can be seen in Fig. $6 \mathrm{~b}$. The overall size of the HTC microspheres is larger, except for GFAS220, while the range of sizes has decreased. This indicates that the addition of $\left(\mathrm{NH}_{4}\right)_{2} \mathrm{SO}_{4}$ enhances HTC formation, allowing for the formation of larger microspheres. Conversely, $\left(\mathrm{NH}_{4}\right)_{2} \mathrm{HPO}_{4}$ produced smaller spherical sizes than $\left(\mathrm{NH}_{4}\right)_{2} \mathrm{SO}_{4}$, indicating that $\mathrm{PO}_{4}{ }^{3-}$ significantly impacts the formation of $\mathrm{HTC}$ materials. It should be noted that the sizing for $\left(\mathrm{NH}_{4}\right)_{2} \mathrm{HPO}_{4}$ was measured from the spherical ends of each joined chain. 
Table 3 List of minimum size, mean and maximum HTC sphere size for all $\mathrm{HTC}$ produced at $220^{\circ} \mathrm{C}$

\begin{tabular}{llll}
\hline Sample & $\begin{array}{l}\text { Minimum size } \\
(\mu \mathrm{m})\end{array}$ & Mean $(\mu \mathrm{m})$ & $\begin{array}{l}\text { Maximum } \\
\text { size }(\mu \mathrm{m})\end{array}$ \\
\hline G220 & 0.7 & 2.8 & 8.6 \\
F220 & 1.0 & 2.5 & 5.5 \\
S220 & 0.9 & 1.6 & 9.7 \\
GF220 & 1.4 & 5.2 & 9.3 \\
GAS220 & 1.2 & 2.7 & 5.97 \\
FAS220 & 1.3 & 3.2 & 7.1 \\
SAS220 & 1.6 & 3.7 & 6.0 \\
GFAS220 & 1.1 & 3.9 & 7.5 \\
GAP220 & 0.6 & 1.7 & 2.8 \\
FAP220 & 1.1 & 2.4 & 6.6 \\
SAP220 & 1.9 & 4.2 & 6.46 \\
\hline
\end{tabular}

\subsection{XPS analysis}

XPS analysis of the non-doped and nitrogen doped HTC from sucrose at $200{ }^{\circ} \mathrm{C}$ is displayed in Table 4. There are subtle differences between each of the HTC materials, for instance carbon content decreased in the order of S200 (81.42 at.\%), SAP200 (80.11 at.\%) and SAS200 (78.75 at.\%). This would suggest that $S 200$ is the most carbonized sample, however deconvolution of the $\mathrm{C} 1 \mathrm{~s}$ peak revealed that the nitrogen doped samples have considerably more $\mathrm{C}=\mathrm{C}$ linkages (S200 29.05 at.\%, SAS200 31.92 at.\%, SAP200 36.16 at.\%). Oxygen content was also seen to decrease with nitrogen doping from 18.58 at.\% in S200 to 14.48 at.\% and 14.17 at.\% for SAS200 and SAP200, respectively. These findings correlate with previous studies $[1,29]$ that indicated that the addition of nitrogen increases the aromaticity of HTC materials.

Examining the nitrogen content, SAP200 had a higher degree of nitrogen incorporation (7.05 at.\%) than SAS200 (4.2 at.\%). However, the same types of functional groups were found when deconvoluting the N1s spectra with in higher concentrations being observed in SAP200. Regarding the ammonium anion, sulfur was observed in the SAS200 sample at low concentrations, indicating that it is incorporated into the carbon structure. A possible peak for phosphorus was observed at $135 \mathrm{eV}$ in the SAP200 sample, however its signal to noise ratio was considerably poor (1.4:1, sulfur in SAS200 was 6.2:1) and thus considered to be below the detection limit of the XPS. This suggests that if phosphorus is incorporated into HTC, it is at very low concentrations ( $>0.1$ at.\%).

To further examine the impact of temperature on hydrothermal carbon, XPS was used to examine the $\left(\mathrm{NH}_{4}\right)_{2} \mathrm{SO}_{4}$ doped HTC series (Fig. 7). As the temperature was increased from 160 to $220{ }^{\circ} \mathrm{C}$, carbon content
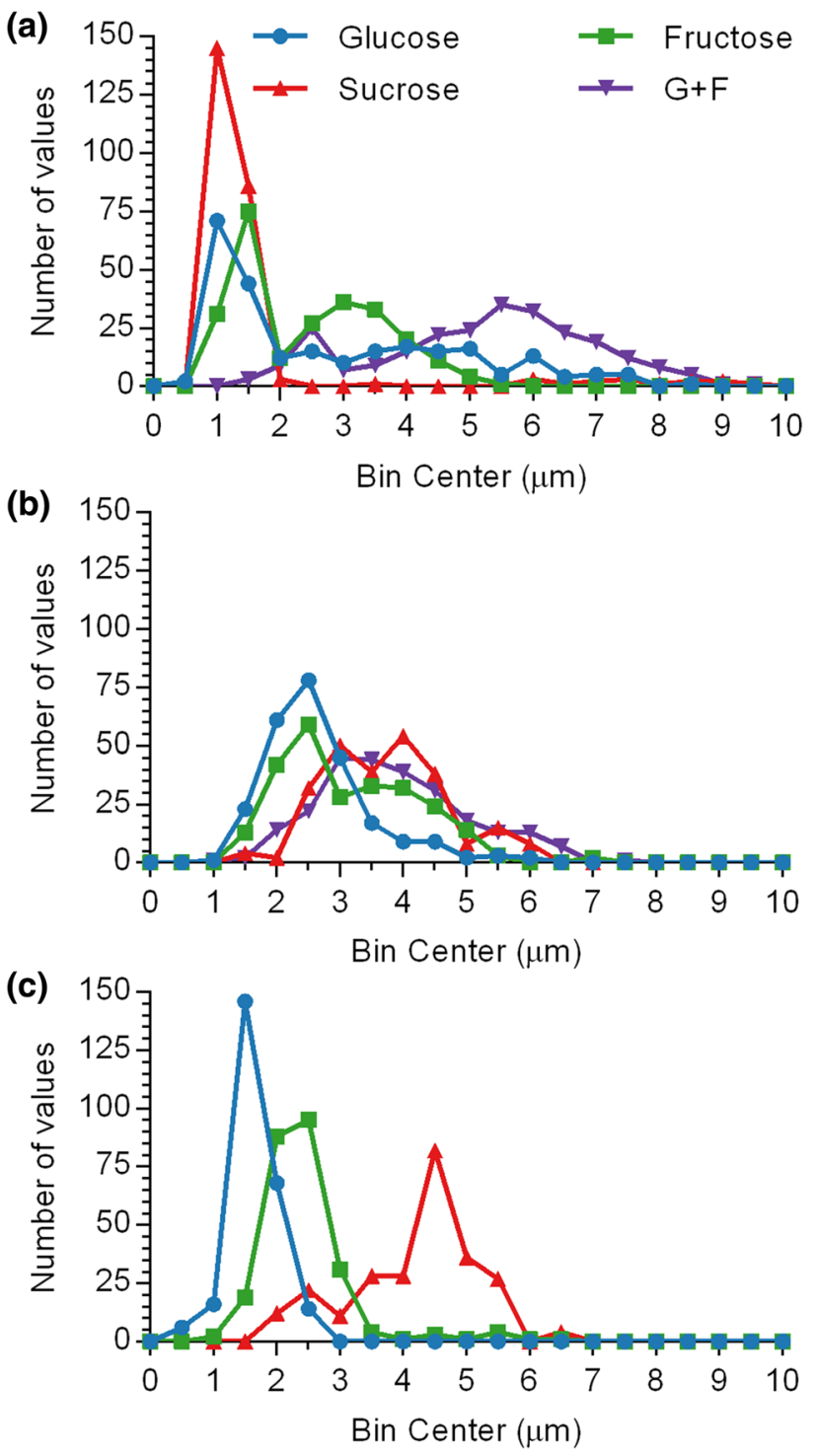

Fig. 6 Histograms of HTC microsphere size for a no nitrogen, $\mathbf{b}$ $\left(\mathrm{NH}_{4}\right)_{2} \mathrm{SO}_{4}$, and $\mathbf{c}\left(\mathrm{NH}_{4}\right)_{2} \mathrm{HPO}_{4}$. Due to the interconnected nature of c $\left(\mathrm{NH}_{4}\right)_{2} \mathrm{HPO}_{4}$, only the end spheres of each joined chain were sized

increased (79.9-81.62 at.\%) while oxygen content decreased (15.31-11.32 at.\%). This result correlates with previous results from the literature, which found that as HTC temperature increased, carbon content increased while oxygen content decreased [18]. Additionally, nitrogen and sulfur content also increased with increasing temperature, indicating that their concentrations can be tuned with temperature.

\subsection{FTIR}

\subsubsection{Analysis of HTC nitrogen bands in FTIR}

The XPS indicated that the surface of the nitrogen doped samples contain a mixture of pyrrolic, pyrrole and amine 
Table 4 XPS analysis of S200, SAS200 and SAP200 for the $\mathrm{C} 1 \mathrm{~s}, \mathrm{O} 1 \mathrm{~s}$ and $\mathrm{N} 1 \mathrm{~s}$ peak regions

\begin{tabular}{|c|c|c|c|c|}
\hline & Functionality (BE; eV) & S200 & SAS200 & SAP200 \\
\hline \multirow[t]{7}{*}{ Carbon } & $C=C(284.1)$ & 29.05 & 31.92 & 36.16 \\
\hline & $\mathrm{C}-\mathrm{C}, \mathrm{C}-\mathrm{H}_{\mathrm{x}}(284.4)$ & 35.17 & 28.47 & 22.81 \\
\hline & C-O- (286.2-288.0) & 21.73 & 12.09 & 15.10 \\
\hline & $\mathrm{C}=\mathrm{O}(287.2-288.1)$ & 9.09 & 4.86 & 3.15 \\
\hline & $\mathrm{COO}^{-}(288.0-289.2)$ & 3.22 & 2.24 & 1.10 \\
\hline & $\mathrm{CO}_{3}(289.0-291.6)$ & 1.74 & 1.23 & 0.46 \\
\hline & Total & 81.42 & 80.11 & 78.75 \\
\hline \multirow[t]{3}{*}{ Oxygen } & $\mathrm{O}=\mathrm{C}(531.2)$ & 10.08 & 8.06 & 7.93 \\
\hline & $-\mathrm{O}-\mathrm{C}(532.9)$ & 8.50 & 5.40 & 6.24 \\
\hline & Total & 18.58 & 14.48 & 14.17 \\
\hline \multirow[t]{5}{*}{ Nitrogen } & Quaternary nitrogen (401.6) & N/A & 0.41 & 0.28 \\
\hline & Pyrrolic, pyridonic and lactam (400.2) & N/A & 1.14 & 1.39 \\
\hline & Amine, amide and nitrile (399.3) & $\mathrm{N} / \mathrm{A}$ & 1.54 & 3.19 \\
\hline & Pyridinic and imines (398.4) & $\mathrm{N} / \mathrm{A}$ & 1.12 & 2.19 \\
\hline & Total & $\mathrm{N} / \mathrm{A}$ & 4.2 & 7.05 \\
\hline Sulfur & & $\mathrm{N} / \mathrm{A}$ & 1.55 & $\mathrm{~N} / \mathrm{A}$ \\
\hline
\end{tabular}

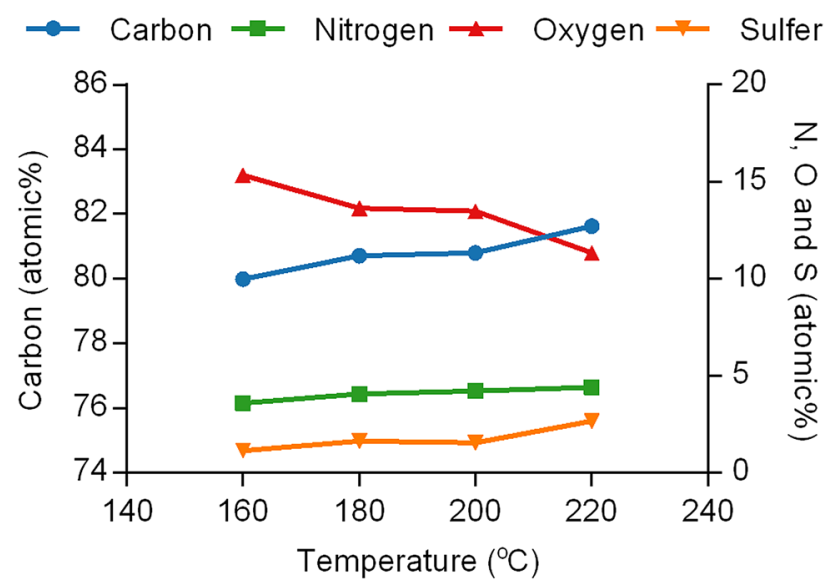

Fig. 7 XPS analysis of the carbon, oxygen and nitrogen content of the $\left(\mathrm{NH}_{4}\right)_{2} \mathrm{SO}_{4}$ doped hydrothermal carbons with temperature. Carbon at.\% is plotted on the left axis and oxygen, nitrogen and sulfur at.\% on the right axis

functionalities. Thus, comparing their FTIR spectra to that of pyrrolic, pyrrole and ethylamine can assist in the identification of regions in the FTIR spectra related to nitrogen functionalities in HTC (Fig. 8). It should be noted however, that the position of ring stretching vibrations on nitrogen rings shift depending on the position and type of substituents attached to the ring [51-53]. For instance, pyrrole displays ring stretching vibrations at 1561,1530 and $1464 \mathrm{~cm}^{-1}$, while 3,4-dimethylpyrrole has peaks at 1580 , 1500 and $1439 \mathrm{~cm}^{-1}$ and 2,5-dimethylpyrrole has peaks at 1593,1515 and $1464 \mathrm{~cm}^{-1}$ for the same ring stretching vibrations [51, 52]. As pyrrole and pyridine have been shown to be attached in multiple configurations on the surface of nitrogen doped HTC [1], this will create broader peaks in the FTIR spectra of nitrogen doped HTC. Evidence of this can be observed when comparing the strong and distinct $\mathrm{C}-\mathrm{N}$ ring stretching vibrations of pyridine at 1580 and $1440 \mathrm{~cm}^{-1}$ to SAS200 and SAP200. The peaks from these stretches are observed in the FTIR, but are broader and weaker than the pure sample.

Despite these limitations, two major $\mathrm{C}-\mathrm{N}$ regions can be assigned relating to ring stretching vibrations $\left(1400-1660 \mathrm{~cm}^{-1}\right)$ and $\mathrm{C}-\mathrm{N}$ stretching vibrations $\left(1100-1300 \mathrm{~cm}^{-1}\right)$ [51-53]. Comparing SAS200 and SAP200, the same peak locations can be observed in both samples, although there are slight differences between the two samples. These variances are probably the result of different concentrations of nitrogen functional groups found in both samples. For instance, SAP200 contains a higher degree of amine and pyridinic functionalities (from XPS) compared to SAS200, which is reflected in the $\mathrm{C}-\mathrm{N} / \mathrm{C}=\mathrm{N}$ ring stretching vibrations between 1300 and $1500 \mathrm{~cm}^{-1}$. Overall, despite $\left(\mathrm{NH}_{4}\right)_{2} \mathrm{HPO}_{4}$ impeding the formation of HTC, the product is chemically similar to the HTC formed with $\left(\mathrm{NH}_{4}\right)_{2} \mathrm{SO}_{4}$.

A comparison between S200 and SAS200 to examine the difference that nitrogen makes on oxygen functionalities is presented in Fig. 7. Firstly, it is important to highlight the main peaks related to furan, as furans make up the main structural motif of HTC. These are located at 1700 ( $C=0$ stretch), $1600(C=C$, stretch $), 1510(C=C$, stretch), 1305 (C-O-C, asymmetric stretch), 1165 (C-O-C, asymmetric stretch), $950(\mathrm{C}-\mathrm{H}$, in/out-of-plane bending), 850 $(\mathrm{C}-\mathrm{H}$, in/out-of-plane bending) and $750(\mathrm{C}-\mathrm{H}$, in/out-ofplane bending) $\mathrm{cm}^{-1}[54,55]$. It can be seen in Fig. 9 that upon the addition of nitrogen, all identified furan peaks have their intensity reduced significantly. 


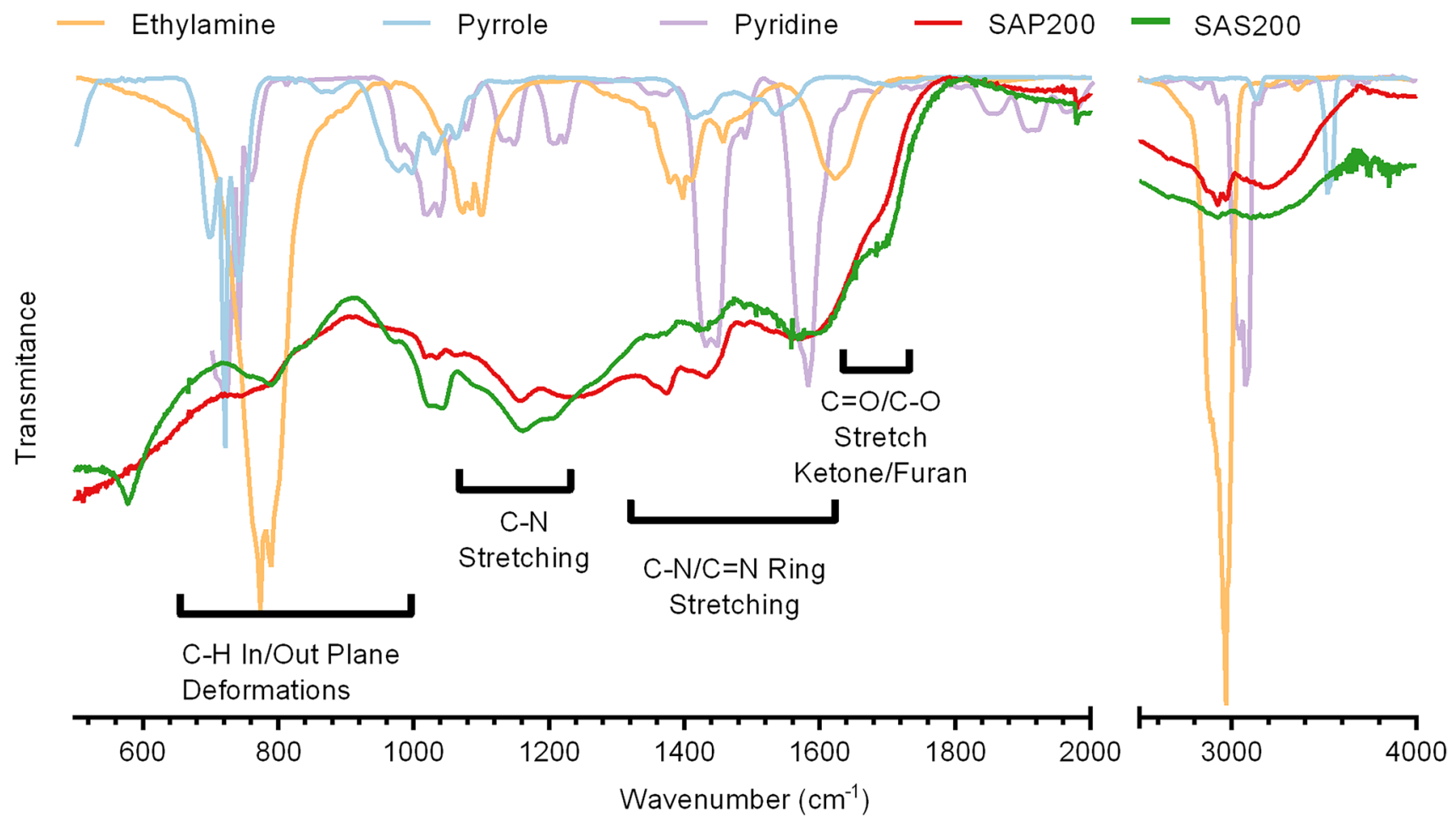

Fig. 8 FTIR spectra of SAS200, SAP200, pyrrole, pyridine and ethylamine with region assignments. The FTIR spectra of pyrrole, pyridine and ethylamine are from NIST references [48-50]

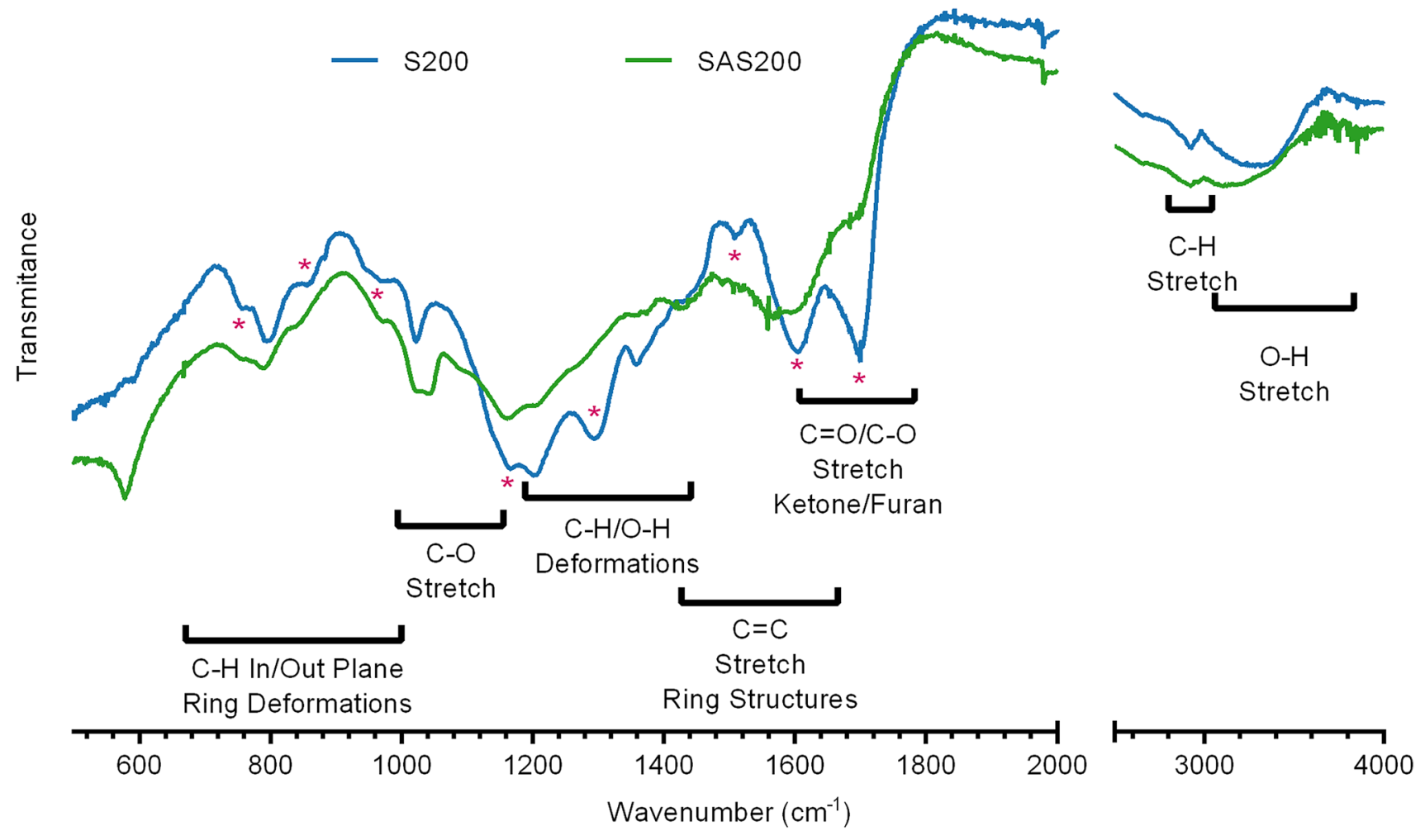

Fig. 9 Comparison of S200 with SAS200 with location of stretch's and deformations related to oxygen functionalities and ring structures. Peaks related to furan rings are marked with * $[54,55]$ 
Additionally, there is an increase in $\mathrm{C}-\mathrm{H}$ in/out plane ring deformations that are associated with aromatic ring structures. This correlates with previous findings $[1,29,45]$ that the incorporation of nitrogen into the HTC structure reduces the degree of furan and increases its aromaticity.

\subsubsection{FTIR comparison of feedstock on HTC produced at $220^{\circ} \mathrm{C}$}

The FTIR of each HTC sample produced at $200{ }^{\circ} \mathrm{C}$ is displayed in Fig. 10. Each spectra displays a number of
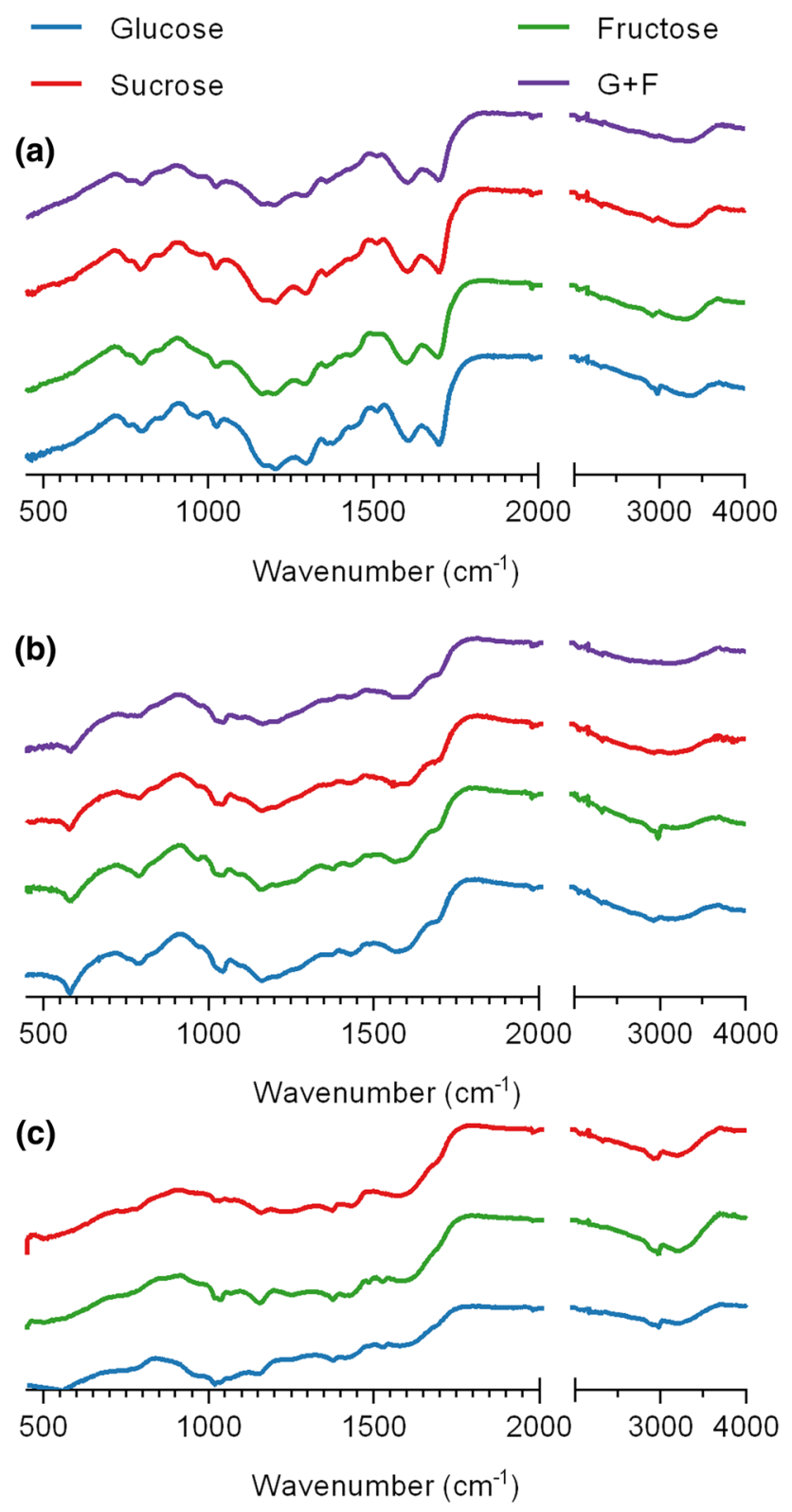

Fig. 10 FTIR spectra of each HTC sample produced at $200 \mathrm{C}$ under a no nitrogen, b $\left(\mathrm{NH}_{4}\right)_{2} \mathrm{SO}_{4}$, and $\mathbf{c}\left(\mathrm{NH}_{4}\right)_{2} \mathrm{HPO}_{4}$. A split in the wavenumber is included to highlight the bands bellow $2000 \mathrm{~cm}^{-1}$ common features independent of saccharide or treatment type, these are; (i) $\mathrm{O}-\mathrm{H}$ stretch between 3200 and $3400 \mathrm{~cm}^{-1}$, (ii) $\mathrm{C}=0$ stretch at $1690 \mathrm{~cm}^{-1}$, (iii) $\mathrm{C}=\mathrm{C}$ aromatic stretch at $1590 \mathrm{~cm}^{-1}$ (iv) $\mathrm{C}-\mathrm{H} / \mathrm{O}-\mathrm{H}$ stretch at $1370 \mathrm{~cm}^{-1}$, (v) C-O stretch at $1275 \mathrm{~cm}^{-1}$, (vi) C-O-C stretch at $1020 \mathrm{~cm}^{-1}$, (vii) $\mathrm{C}=\mathrm{C}$ aromatic stretch at $985 \mathrm{~cm}^{-1}$, and (viii) $\mathrm{C}-\mathrm{H}$ aromatic stretch at $770 \mathrm{~cm}^{-1}$.

Interestingly, there is almost no difference between the spectra of each saccharide in each series, indicating that each HTC is chemically similar regardless of precursor. However, there are differences between each treatment method in the intensity of the stretches, with minor shifting of peaks also occurring. For example, the $\mathrm{C}=\mathrm{O}$ stretch at $1690 \mathrm{~cm}^{-1}$ is a prominent peak in the neutral and $\mathrm{Na}_{2} \mathrm{SO}_{4}$ series, while it is a shoulder in the $\left(\mathrm{NH}_{4}\right)_{2} \mathrm{SO}_{4}$ and $\left(\mathrm{NH}_{4}\right)_{2} \mathrm{HPO}_{4}$ series. Additionally, the $\mathrm{C}=\mathrm{C}$ aromatic stretch shifts its position and is located at 1602 and 1600 for the neutral and $\mathrm{Na}_{2} \mathrm{SO}_{4}$ series, while it is located at 1588 and 1589 in the $\left(\mathrm{NH}_{4}\right)_{2} \mathrm{SO}_{4}$ and $\left(\mathrm{NH}_{4}\right)_{2} \mathrm{HPO}_{4}$ series. This suggest there is a change in the local chemical environment upon the incorporation of nitrogen into these samples, as the peak heights and locations tend to correlate between the neutral and $\mathrm{Na}_{2} \mathrm{SO}_{4}$ series, while a similar correlation can be found between the $\left(\mathrm{NH}_{4}\right)_{2} \mathrm{SO}_{4}$ and $\left(\mathrm{NH}_{4}\right)_{2} \mathrm{HPO}_{4}$ series.

\section{Conclusion}

The hydrothermal carbonization of glucose, fructose and sucrose under different temperatures and ammonium salts produced a wide range of yields, sizes and chemical morphologies depending on the temperature and ammonium salt added. In general, the yield of HTC increased with increasing temperature, with a maximum yield of $45.0 \mathrm{wt} \%$ achieved using an equimolar mixture of glucose and fructose. Adding $\left(\mathrm{NH}_{4}\right)_{2} \mathrm{SO}_{4}\left(\mathrm{NH}_{4}\right)_{2} \mathrm{HPO}_{4}$ or $\mathrm{NaSO}_{4}$ increased the yield of $\mathrm{HTC}$ at lower temperatures, although, the yield of $\left(\mathrm{NH}_{4}\right)_{2} \mathrm{HPO}_{4}$ was stagnant at $\sim 8 \mathrm{wt} \%$ for glucose and fructose and $\sim 13 \mathrm{wt} \%$ for sucrose, regardless of temperature. The SEM results displayed a range of spherical sizes for the $\mathrm{HTC}$, while $\left(\mathrm{NH}_{4}\right)_{2} \mathrm{HPO}_{4}$ produced several interconnected shapes.

The XPS analysis revealed that carbon content increased, while oxygen content decreased upon the addition of ammonium salts. The nitrogen doped HTC materials had similar nitrogenated functionalities, however the nitrogen content increased significantly in the $\left(\mathrm{NH}_{4}\right)_{2} \mathrm{HPO}_{4}$ doped $\mathrm{HTC}$ material from 4.2 at.\% in $\left(\mathrm{NH}_{4}\right)_{2} \mathrm{SO}_{4} \mathrm{HTC}$ to 7.05 at.\%. This indicated that the nitrogen content in HTC materials can be altered by changing the anion. Additionally, the $\left(\mathrm{NH}_{4}\right)_{2} \mathrm{SO}_{4} \mathrm{HTC}$ contained sulfur groups, while the $\left(\mathrm{NH}_{4}\right)_{2} \mathrm{HPO}_{4} \mathrm{HTC}$ did not have phosphate incorporated into the structure. 
The FTIR analysis indicated that there was very little difference between saccharides in each series, while significant differences were found between the normal solution, $\left(\mathrm{NH}_{4}\right)_{2} \mathrm{SO}_{4}$ and $\left(\mathrm{NH}_{4}\right)_{2} \mathrm{HPO}_{4}$. Using reference spectra, two major $\mathrm{C}-\mathrm{N}$ regions were assigned at $1400-1660 \mathrm{~cm}^{-1}$ for $\mathrm{C}-\mathrm{N}$ ring stretching vibrations and at $1100-1300 \mathrm{~cm}^{-1}$ for $\mathrm{C}-\mathrm{N}$ stretching vibrations. Additionally, the FTIR indicated that the addition of nitrogen was shown to decrease the degree of peaks related to the furan structure of HTC. Several peaks were also found to be common between samples that represented, $-\mathrm{OH}, \mathrm{C}=\mathrm{O}, \mathrm{C}=\mathrm{C}$ aromatic, $\mathrm{C}-\mathrm{O}$, $\mathrm{C}-\mathrm{O}-\mathrm{C}$ functionalities, although these peaks tended to be slightly shifted in the $\left(\mathrm{NH}_{4}\right)_{2} \mathrm{SO}_{4}$ and $\left(\mathrm{NH}_{4}\right)_{2} \mathrm{HPO}_{4}$ added HTC. This suggested that there is a change in the local chemical environment upon the incorporation of nitrogen into these samples. Overall, the temperature and saccharide used had more impact on the yield, while the incorporation of $\left(\mathrm{NH}_{4}\right)_{2} \mathrm{SO}_{4}$ and $\left(\mathrm{NH}_{4}\right)_{2} \mathrm{HPO}_{4}$ lowered the activation energy required to produce $\mathrm{HTC}$ and modified the overall chemical structure.

Acknowledgements K.G.L. acknowledges the University of Newcastle for provision of a Ph.D. scholarship.

\section{Compliance with ethical standards}

Conflict of interest The authors express that there are no conflicts of interest with the work contained in this manuscript.

Open Access This article is distributed under the terms of the Creative Commons Attribution 4.0 International License (http://creativeco mmons.org/licenses/by/4.0/), which permits unrestricted use, distribution, and reproduction in any medium, provided you give appropriate credit to the original author(s) and the source, provide a link to the Creative Commons license, and indicate if changes were made.

\section{References}

1. Latham KG et al (2016) Molecular structures driving pseudocapacitance in hydrothermal nanostructured carbons. RSC Adv 6(16):12964-12976

2. Jain A, Balasubramanian R, Srinivasan MP (2016) Hydrothermal conversion of biomass waste to activated carbon with high porosity: a review. Chem Eng J 283:789-805

3. Wang $\mathrm{Y}$ et al (2015) Hydrothermal preparation of highly porous carbon spheres from hemp (Cannabis sativa L.) stem hemicellulose for use in energy-related applications. Ind Crops Prod 65:216-226

4. Qiang RB et al (2015) Monodisperse carbon microspheres derived from potato starch for asymmetric supercapacitors. Electrochim Acta 167:303-310

5. Chen XJ et al (2015) Fabrication of hierarchical cabbage-like carbonaceous materials by one-step cobalt-assisted hydrothermal carbonization of furfural. Microporous Mesoporous Mater 210:149-160
6. Feng SS et al (2014) Hydrothermal synthesis of ordered mesoporous carbons from a biomass-derived precursor for electrochemical capacitors. Nanoscale 6(24):14657-14661

7. Fan $Y$ et al (2014) Micro-mesoporous carbon spheres derived from carrageenan as electrode material for supercapacitors. J Power Sources 268:584-590

8. Liang JY et al (2014) Expeditious fabrication of flower-like hierarchical mesoporous carbon superstructures as supercapacitor electrode materials. J Mater Chem A 2(40):16884-16891

9. Sevilla M et al (2014) Supercapacitive behavior of two glucosederived microporous carbons: direct pyrolysis versus hydrothermal carbonization. Chemelectrochem 1(12):2138-2145

10. Wen $Z$ et al (2007) Hollow carbon spheres with wide size distribution as anode catalyst support for direct methanol fuel cells. Electrochem Commun 9(8):1867-1872

11. Latham KG et al (2014) Nitrogen doping of hydrochars produced hydrothermal treatment of sucrose in $\mathrm{H}_{2} \mathrm{O}, \mathrm{H}_{2} \mathrm{SO}_{4}$, and $\mathrm{NaOH}$. ACS Sustain Chem Eng 2(4):755-764

12. Fan $X$ et al (2013) Chitosan derived nitrogen-doped microporous carbons for high performance $\mathrm{CO}_{2}$ capture. Carbon 61:423-430

13. Si W et al (2013) Tunable N-doped or dual N,S-doped activated hydrothermal carbons derived from human hair and glucose for supercapacitor applications. Electrochim Acta 107:397-405

14. Wang C et al (2013) Sustainable synthesis of phosphorus- and nitrogen-co-doped porous carbons with tunable surface properties for supercapacitors. J Power Sources 239:81-88

15. Braghiroli FL et al (2015) Hydrothermally treated aminated tannin as precursor of $\mathrm{N}$-doped carbon gels for supercapacitors. Carbon 90:63-74

16. Chen P et al (2013) Hydrothermal synthesis of macroscopic nitrogen-doped graphene hydrogels for ultrafast supercapacitor. Nano Energy 2(2):249-256

17. Guo DY et al (2015) Hydrangea-like multi-scale carbon hollow submicron spheres with hierarchical pores for high performance supercapacitor electrodes. Electrochim Acta 176:207-214

18. Sevilla M, Fuertes AB (2009) Chemical and structural properties of carbonaceous products obtained by hydrothermal carbonization of saccharides. Chem Eur J 15(16):4195-4203

19. Ming J et al (2013) Sodium salt effect on hydrothermal carbonization of biomass: a catalyst for carbon-based nanostructured materials for lithium-ion battery applications. Green Chem 15(10):2722-2726

20. Song L-T et al (2016) Sustainable hydrothermal carbonization synthesis of iron/nitrogen-doped carbon nanofiber aerogels as electrocatalysts for oxygen reduction. Small 12(46):6398-6406

21. Braghiroli FL et al (2012) Nitrogen-doped carbon materials produced from hydrothermally treated tannin. Carbon 50(15):5411-5420

22. Tan J et al (2015) Nitrogen-doped porous carbon derived from citric acid and urea with outstanding supercapacitance performance. Electrochim Acta 178:144-152

23. Baccile $\mathrm{N}$ et al (2009) Structural characterization of hydrothermal carbon spheres by advanced solid-state MAS ${ }^{13} \mathrm{C}$ NMR investigations. J Phys Chem C 113(22):9644-9654

24. Horvat J et al (1985) Mechanism of levulinic acid formation. Tetrahedron Lett 26(17):2111-2114

25. Patil SKR, Lund CRF (2011) Formation and growth of humins via aldol addition and condensation during acid-catalyzed conversion of 5-hydroxymethylfurfural. Energy Fuels 25(10):4745-4755

26. Daorattanachai $P$ et al (2012) 5-Hydroxymethylfurfural production from sugars and cellulose in acid- and base-catalyzed conditions under hot compressed water. J Ind Eng Chem (Amst Neth) 18(6):1893-1901

27. Sevilla M, Fuertes $A B$ (2009) The production of carbon materials by hydrothermal carbonization of cellulose. Carbon 47(9):2281-2289 
28. Zhang $M$ et al (2012) Hydrophobic precipitation of carbonaceous spheres from fructose by a hydrothermal process. Carbon 50(6):2155-2161

29. Latham KG et al (2017) Synchrotron based NEXAFS study on nitrogen doped hydrothermal carbon: insights into surface functionalities and formation mechanisms. Carbon 114:566-578

30. Antal MJ Jr, Mok WSL, Richards GN (1990) Mechanism of formation of 5-(hydroxymethyl)-2-furaldehyde from D-fructose and sucrose. Carbohydr Res 199(1):91-109

31. Oomori T et al (2004) Hydrolysis of disaccharides containing glucose residue in subcritical water. Biochem Eng J 18(2):143-147

32. Kabyemela BM et al (1997) Kinetics of glucose epimerization and decomposition in subcritical and supercritical water. Ind Eng Chem Res 36(5):1552-1558

33. Kabyemela BM et al (1999) Glucose and fructose decomposition in subcritical and supercritical water: detailed reaction pathway, mechanisms, and kinetics. Ind Eng Chem Res 38(8):2888-2895

34. Asghari FS, Yoshida $\mathrm{H}$ (2007) Kinetics of the decomposition of fructose catalyzed by hydrochloric acid in subcritical water: formation of 5-hydroxymethylfurfural, levulinic, and formic acids. Ind Eng Chem Res 46(23):7703-7710

35. Daorattanachai $P$ et al (2012) Conversion of fructose, glucose, and cellulose to 5-hydroxymethylfurfural by alkaline earth phosphate catalysts in hot compressed water. Carbohydr Res 363:58-61

36. Asghari FS, Yoshida H (2006) Acid-catalyzed production of 5-hydroxymethylfurfural from $D$-fructose in subcritical water. Ind Eng Chem Res 45(7):2163-2173

37. Klingler D, Vogel $H(2010)$ Influence of process parameters on the hydrothermal decomposition and oxidation of glucose in sub- and supercritical water. J Supercrit Fluids 55(1):259-270

38. Saito T et al (2009) Subcritical water reaction behavior of D-glucose as a model compound for biomass using two different continuous-flow reactor configurations. Chem Eng Technol 32(4):527-533

39. Yan $X$ et al (2007) Production of lactic acid from glucose by alkaline hydrothermal reaction. J Mater Sci 42(24):9995-9999

40. Jin F et al (2008) Hydrothermal conversion of carbohydrate biomass into formic acid at mild temperatures. Green Chem 10:612-615

41. Knezevic D, van Swaaij WPM, Kersten SRA (2009) Hydrothermal conversion of biomass: I, glucose conversion in hot compressed water. Ind Eng Chem Res 48(10):4731-4743
42. Yang G, Pidko EA, Hensen EJM (2012) Mechanism of Bronsted acid-catalyzed conversion of carbohydrates. J Catal 295:122-132

43. Promdej C, Matsumura Y (2011) Temperature effect on hydrothermal decomposition of glucose in sub- and supercritical water. Ind Eng Chem Res 50(14):8492-8497

44. Jing $Q$, Lu X (2008) Kinetics of non-catalyzed decomposition of glucose in high-temperature liquid water. Chin J Chem Eng 16(6):890-894

45. Baccile N et al (2011) Structural insights on nitrogen-containing hydrothermal carbon using solid-state magic angle spinning ${ }^{13} \mathrm{C}$ and ${ }^{15} \mathrm{~N}$ nuclear magnetic resonance. J Phys Chem $\mathrm{C}$ 115(18):8976-8982

46. Horvat $J$ et al (1986) Mechanism of levulinic acid formation in acid catalyzed hydrolysis of 2-(hydroxymethyl)furan and 5-(hydroxymethyl)-2-furancarboxaldehyde. Croat Chem Acta 59(2):429-438

47. Zhao L et al (2010) Sustainable nitrogen-doped carbonaceous materials from biomass derivatives. Carbon 48(13):3778-3787

48. Pyrrole. In: Mallard PJLaWG (ed) NIST Chemistry WebBook, NIST Standard Reference Database Number 69. National Institute of Standards and Technology, Gaithersburg

49. Pyridine. In: Linstrom PJ, Mallard WG (eds) NIST Chemistry WebBook, NIST Standard Reference Database Number 69. National Institute of Standards and Technology, Gaithersburg

50. Ethylamine. In: Mallard PJLaWG (ed) NIST Chemistry WebBook, NIST Standard Reference Database Number 69. National Institute of Standards and Technology, Gaithersburg

51. Jones RA (1967) Pyrrole studies - XI. The infra-red spectra of 2-substituted-1-methylpyrroles. Spectrochim Acta Part A Mol Spectrosc 23(7):2211-2213

52. Jones R (1966) Pyrrole studies. IX. The infrared spectra of 1-substituted pyrroles. Aust J Chem 19(2):289-296

53. Swoboda AR, Kunze GW (1965) Infrared study of pyridine adsorbed on montmorillonite surfaces. Clays Clay Miner 13(1):277-288

54. Wrobel JT, Galuszko K (1965) IR spectra of some 2-, and 3-substituted furan derivatives. Tetrahedron Lett 6(49):4381-4385

55. Yao L et al (1999) The substituent structures and characteristic infrared spectra of alpha-furan esters. Guang Pu Xue Yu Guang Pu Fen Xi 19(1):32-34 